\title{
TECNOLOGÍAS DIGITALES Y DELITOS AMBIENTALES ${ }^{1}$
}

\section{DIGITAL TECHNOLOGIES AND ENVIRONMENTAL CRIMES}

\section{Lorenzo Mateo Bujosa Vadell}

Catedrático de Derecho Procesal Universidad de Salamanca, España. E-mail: lbujosa@usal.es

RESUMEN: El artículo aborda los drones como medios de prueba, de acuerdo con el pronóstico legislativo español, y el procedimiento de valoración probatoria.

PALABRAS-CLAVE: Tecnologías digitales; delitos ambientales; prueba.

ABSTRACT: This paper deals with drones as evidence, according to the Spanish law, and the procedure for valuating the proof.

KEY WORDS: Digital technologies; environmental crimes; proof.

SUMARIO: 1.- Introducción.- 2.- La revolución digital.- 3.- Los drones: un elemento de la realidad jurídica.-4.- Los drones como instrumento de investigación penal. 4.1.- Referencia al marco normativo vigente. 4.2.- Plan Estratégico del Gobierno 2018-2021. 4.3.- Los drones en la LECrim. 4.4.- Eventual afección a derechos fundamentales.- 5.- Drones y medios de prueba: las dificultades de una LECrim del siglo XIX.- 6.- Algunos problemas de valoración probatoria.

\section{1.- INTRODUCCIÓN}

Los cambios acelerados de la realidad plantean continuas cuestiones que debe resolver el Derecho. Así ha ocurrido siempre con la evolución tecnológica y sus

\footnotetext{
${ }^{1}$ Artigo recebido em 21/08/2019, sob dispensa de revisão.
} 
implicaciones jurídicas y, por supuesto sigue ocurriendo en el contexto de los cambios que implica la digitalización del tráfico jurídico, la aparición de nuevos artefactos que pueden ser útiles para múltiples finalidades con relevancia jurídica o que plantean dilemas éticamente complejos que nos ocuparán en los próximos años como las consecuencias de la inteligencia artificial en distintos aspectos procesales, incluida la presencia procesal de los robots o el mismísimo juicio jurisdiccional, temas que se están discutiendo ya en múltiples foros y en una incipiente y sugestiva bibliografía hispana ${ }^{2}$, que sigue la senda de abundantes y anteriores estudios en otros países ${ }^{3}$, y en especial en el ámbito anglosajón ${ }^{4}$.

Todo ello merece estudios y discusiones profundas que no pueden tener cabida en un texto de las dimensiones limitadas del presente. Todavía no hay certezas claras en todos estos aspectos, por mucho que haya pasado tiempo desde que venimos hablando de la informatización del proceso, del expediente digital, del uso y los límites videoconferencia. Estos temas que tienen ya poco de nuevos sin duda merecen atención académica todavía, pero la reflexión apunta ya a nuevas cuestiones que, de algún modo, van siendo recogidas en algunas reformas legislativas como la de la reforma de octubre en la legislación procesal penal española 5 .

\footnotetext{
${ }^{2}$ Vid. BONET NAVARRO, José, "La tutela judicial de los derechos no humanos. De la tramitación electrónica al proceso con robots autónomos", CEFLegal: revista práctica de derecho. Comentarios y casos prácticos, núm. 208, 2018, pp. 55-92, y NIEVA FENOLL, Jordi, Inteligencia artificial y proceso judicial, Marcial Pons, Madrid, 2018.

${ }^{3}$ Valga como ejemplo la famosa serie de Isaac ASIMOV, que ya introducía interesantes valoraciones éticas respecto al trato con robots y al comportamiento de los mismos. Sobre esa vertiente de filosofia moral, es imprescindible atender a las reflexiones de Adela CORTINA ORTS, "El estatuto de la ética aplicada. Hermenéutica crítica de las actividades humanes", Isegoría, núm. 13, 1996, pp. 119-134.

${ }^{4}$ Vid., entre otros, WALTON, Douglas, Argumentation Methods for Artificial Intelligence in Law, Springer, New York, 2005; CHOPRA, Samir, WHITE, Laurence F., A legal Theory for Autonomous Artificial Agents, The University of Michigan Press, Ann Arbor, 2011; PAGALLO, Ugo, The Laws of Robots. Crimes, Contracts, and Torts, Springer, Dordrect, 2013; CHACE, Calum, Surviving AI, Three Cs., 2015; RUSSELL, Stuart J., NORVIG, Peter, Artificial Intelligence. A Modern Approach, Pearson, $3^{\text {rd }}$ ed., Harlow, 2016; KAPLAN, Jerry, Artificial Intelligence. What everyone needs to know, Oxford University Press, New York, 2016; JORDAN, John, Robots, MIT Press, Cambridge, 2016; TEGMARK, Max, Life 3.O. Being human in the age of Artificial Intelligence, Penguin, New York, 2018; BROCKMAN, John (Ed.), Possible Minds. Twenty-Five Ways of Looking at AI, Penguin Press, New York, 2019.

${ }^{5}$ Me refiero a la introducida por la Ley Orgánica 13/2015, de 5 de octubre, de modificación de la Ley de Enjuiciamiento Criminal para el fortalecimiento de las garantías procesales y la regulación de las medidas de investigación tecnológica. El primer párrafo del apartado IV de su preámbulo constata la situación existente en el momento de la promulgación de esta reforma: "La Ley de Enjuiciamiento Criminal no ha podido sustraerse al paso del tiempo. Renovadas formas de delincuencia ligadas al uso de las nuevas tecnologías han puesto de manifiesto la insuficiencia de un cuadro normativo concebido para tiempos bien distintos. Los flujos de información generados por los sistemas de comunicación telemática advierten de las posibilidades que se hallan al alcance del delincuente, pero también proporcionan poderosas herramientas de investigación a los poderes públicos. Surge así la necesidad de encontrar un delicado equilibrio entre la capacidad del Estado para hacer
} 
En las páginas que siguen me limitaré a ordenar algunas ideas respecto a la utilización de unos medios tecnológicos concretos en el proceso penal; medios que están empezando a convertirse en habituales en nuestra vida cotidiana, incluso como aparatos de entretenimiento doméstico. Como se podrá ver, se trata de un ejemplo valioso de cómo estos avances tecnológicos nos plantean cuestiones a las que debemos dar respuesta fundada los juristas preocupados en reforzar las garantías de los justiciables. Una vez más hay que tratar de mantener una perspectiva prudente, de modo que el embelesamiento por lo que la tecnología puede ofrecernos no nos obnubile nuestra capacidad crítica de limitar los derechos fundamentales sólo en los casos en que constitucionalmente sea legítimo. Véase, pues, que, aunque tratemos de objetos de estudio -"relativamente"- nuevos, continuamos revoloteando en torno al eterno dilema entre eficacia y garantía.

\section{2.- LA REVOLUCIÓN DIGITAL}

Conviene, con la imprescindible brevedad, contextualizar la problemática, aún de manera genérica. No es oportuno olvidar que los desafíos contemporáneos se están enmarcando en la llamada "nueva revolución tecnológica", como una vuelta de tuerca de la historia. Sin que eso implique necesariamente una visión optimista hacia el progreso de los tiempos, ya que todo avance conlleva sus ventajas y al mismo tiempo sus riesgos y peligros. De ahí la importancia de tener en cuenta no sólo la perspectiva jurídica de alcance constitucional, sino además, abriendo un poco más el objetivo -si se son permite la expresión-, los alcances éticos que se derivan de todo ello.

Desde luego, la sensación de aceleración de los cambios es generalizada y no es ajeno a ello la inmersión en la que nos encontramos en un mundo desigualmente globalizado

\footnotetext{
frente a una fenomenología criminal de nuevo cuño y el espacio de exclusión que nuestro sistema constitucional garantiza a cada ciudadano frente a terceros. Por muy meritorio que haya sido el esfuerzo de jueces y tribunales para definir los límites del Estado en la investigación del delito, el abandono a la creación jurisprudencial de lo que ha de ser objeto de regulación legislativa ha propiciado un déficit en la calidad democrática de nuestro sistema procesal, carencia que tanto la dogmática como instancias supranacionales han recordado. Recientemente, el Tribunal Constitucional ha apuntado el carácter inaplazable de una regulación que aborde las intromisiones en la privacidad del investigado en un proceso penal. Hoy por hoy, carecen de cobertura y su subsanación no puede obtenerse acudiendo a un voluntarista expediente de integración analógica que desborda los límites de lo constitucionalmente aceptable. Solo así se podrá evitar la incidencia negativa que el actual estado de cosas está proyectando en relación con algunos de los derechos constitucionales que pueden ser objeto de limitación en el proceso penal".
} 
y sometido a las vorágines ultraliberales, trufadas sin embargo de proteccionismos autoritarios, igualmente peligrosos para la incolumidad de la integridad de la dignidad del hombre y de los grupos en que se integra ${ }^{6}$.

Todo ello no debe perderse de vista cuando nos acercamos a examinar lo que se ha dado en llamar la "cuarta revolución industrial" , como consecuencia de la transformación de la humanidad que conlleva la generalización de las nuevas tecnologías en su sentido amplio. Como en todas las revoluciones industriales, se observa una situación de incertidumbre a una escala mayor que en las anteriores, porque el impacto es casi simultáneo en todos los continentes y en muchas de las sociedades del momento actual. Se ha hablado de la evolución a un ritmo exponencial mucho más elevado, de una mucho mayor amplitud y profundidad y de una transformación de sistemas complejos en diversos planos, públicos y privados, individuales y sociales.

Es llamativo, como señala $\mathrm{SCHWAB}^{8}$, que desde un punto de vista social, uno de los efectos más relevantes de la digitalización es el surgimiento de la sociedad "centrada en el yo", es decir: "un proceso de individualización y aparición de nuevas formas de pertenencia y de comunidad. Al contrario de lo que sucedía en el pasado, la noción de 'pertenencia' a una comunidad se define hoy más por intereses, valores individuales y proyectos personales que por el espacio (la comunidad), el trabajo y la familia”. Si ello es así, todo ello conducirá a medio plazo a transformaciones del Derecho que todavía no acabamos de intuir, pero para las que es necesario prepararse, sin olvidarse en la imprescindible adaptación en la que estamos entrando que en el centro debe seguir estando el ser humano, entendido como ser social, por mucho que la socialización sufra

\footnotetext{
${ }^{6}$ Cuando adoptamos estos puntos de vista para una contextualización de la cuestión objeto de estudio no debemos olvidar la incidencia general de los valores superiores de la Constitución, es especial la libertad, la igualdad y la justícia, junto con el pluralismo político que permite introducir diversas opciones de equilibrio entre los mencionados valores, todas ellas legítimas siempre que no supongan anular de facto la eficàcia de uno de los valores a combinar. Utilizando un lenguaje alexiano, podemos considerar como mandatos de optimización las exigències del apartado segundo del articulo noveno de la Constitución política española actualmente vigente: "Corresponde a los poderes públicos promover las condiciones para que la libertad y la igualdad del individuo y de los grupos en que se integra sean reales y efectivas; remover los obstáculos que impidan o dificulten su plenitud y facilitar la participación de todos los ciudadanos en la vida política, económica, cultural y social.”.

${ }^{7}$ SCHWAB, Klaus, La cuarta revolución industrial, Debate, Barcelona, 2016.

${ }^{8}$ SCHWAB, Klaus, La cuarta revolución..., op. cit., p. 122.
} 
extraordinarias mutaciones y que los riesgos para los derechos fundamentales procedan de amenazas de naturaleza insospechada ${ }^{9}$.

\section{3.- LOS DRONES: UN ELEMENTO DE LA REALIDAD JURÍDICA}

Como antes avanzaba, las consecuencias jurídicas de todos estos cambios son monumentales, a pesar de que el legislador y los operadores jurídicos no seamos del todo conscientes de hasta qué punto será necesaria la transformación jurídica, es decir, la recepción jurídica de esas modificaciones individuales y sociales. Por ello, el propósito de este breve estudio es mucho más limitado. Se limitará a analizar uno de los nuevos instrumentos, teniendo en cuenta la mayoría de sus grandes posibilidades, para luego acercarnos a considerar su aplicación en el proceso y, una vez más, a tratar de analizar las exigencias de equilibrio que plantea su uso y las prevenciones que tanto los fiscales, como los jueces, así como los abogados, deben adoptar para evitar que la investigación y el enjuiciamiento jurisdiccional sufran deformaciones ilegítimas que pudieran suponer vías de corrupción del sistema procesal.

La palabra más usualmente utilizada para referirnos a los artefactos protagonistas de estas páginas es la de "dron”. Término procedente del inglés drone, que ha sido acogida por el Diccionario de la Lengua Española de la Real Academia y que se define como "aeronave no tripulada". La novedad es, por tanto, escasa cuando pensamos en que ya hace decenios todos hemos visto aparatos teledirigidos, incluso hemos podido jugar con ellos. Sin embargo, sí hay nuevas características que hacen que estemos ante una realidad distinta.

La novedad, como decía, no está en que se trate de una aeronave no tripulada; la innovación se encuentra sobre todo en su generalización social, en su flexibilidad, en la facilidad de manejo, en la variedad de aplicaciones, que están en plena efervescencia y que ya han planteado la necesidad de una ordenación regulatoria para evitar perjuicios y

\footnotetext{
${ }^{9}$ Esta concepción afectará sin duda a la consideración del espacio ambiental, sobre el que entendemos todavía justificada una concepción antropocéntrica, superadora sin embargo de la "gran desmesura antropocéntrica" de la que hablan LORENZETTI, Ricardo Luis, y LORENZETTI, Pablo, Principios e instituciones de Derecho ambiental, La Ley, Madrid, 2019: “... ya no es posible admitir que existe un derecho para todos de usar los bienes en cualquier cantidad y para cualquier propósito".
} 
complicaciones no deseadas, como por ejemplo, la interferencia con otros sistemas aéreos ${ }^{10}$, que no se resuelve con la suelta de halcones, como es tradicional para evitar el sobrevuelo de aves que puedan poner en riesgo la actividad de los motores de las aeronaves ordinarias ${ }^{11}$.

No debemos olvidar, sin embargo, que también hay otras denominaciones usuales para referirnos a los drones, así se habla en lengua castellana de VANT (vehículos no tripulados) y en inglés de UAVs (Unmanned Aerial Vehicle) o de RAP (Remotely Piloted Aircraft). Todas ellas se refieren al mismo concepto de vehículo, usualmente de pequeñas o muy pequeñas dimensiones que se maneja de manera remota, con características diversas según los tipos concretos, pero con grandes posibilidades debido a su escaso peso, a la simplicidad de la conducción a distancia y a su amplitud de eventuales funciones ${ }^{12}$.

Sin entrar todavía en la perspectiva jurídica de estos artefactos, debemos constatar la multiplicidad de usos posibles ${ }^{13}$. Sin duda se está popularizando como un instrumento de ocio de ya podemos ver en los parques y jardines de nuestras ciudades, con frecuencia manejados por menores. Pero también son usados como dispositivos periodísticos, dada la capacidad de llevar cámaras que se pueden activar también de manera remota, así el dron llega donde el ser humano no alcanza para obtener fotografías que de otro modo sería complicado o, muy probablemente imposible, obtener; simplemente para obtener información, aunque no sea gráfica, pero útil para las investigaciones periodísticas. Existe ya la posibilidad técnica de utilizar estos aparatos como medio de transporte ligero para cargas pequeñas o medianas, que puedan abaratar los costes de otro tipo de transporte ${ }^{14}$.

\footnotetext{
${ }^{10}$ Recuérdese la reciente paralización de la actividad aérea en el aeropuerto principal de la ciudad de Londres por el sobrevuelo de drones en la ruta reservada a los aviones, con los peligros que ello conlleva para el tráfico regular: https://cnnespanol.cnn.com/2019/01/08/detienen-los-despegues-de-aviones-en-el-aeropuerto-de-heathrow-enlondres-tras-avistamiento-de-dron/

${ }^{11}$ Es bastante conocida la película Sully, dirigida por Clint Eastwood, y que cuenta la historia real del comandante de un avión norteamericano, Chesly Sullenberger, cuyo avión, en enero de 2009, al poco de despegar del aeropuerto de La Guardia en Nueva York, sufrió un grave problema en sus motores debido al choque con una bandada de gansos.

${ }^{12}$ BARRIO ANDRÉS, Moisés, "Drones. Concepto, clases e historia. Usos actuales. El Derecho de los drones", en Derecho de los drones (Dir. Moisés Barrio Andrés), La Ley, Madrid, 2018, pp. 36-37, determina los elementos estructurales comunes, a pesar de que cada dron tanga una composición técnica y mecànica diferente: chasis o carcasa; motores; hélices; placa controladora de vuelo; sensores y sistema de alimentación eléctrica.

${ }^{13}$ Vid. ALONSO PUIG, Alejandro, Drones profesionales. Usos y Técnica, Quark Robotics, 2016.

${ }^{14}$ Desde hace ya bastantes años la enorme empresa de comercio electrónico Amazon ha mostrado su interés por beneficiarse del reparto de su mercancía mediante drones, que aumentarían la rapidez y evitarían, en ciertos lugares inseguros, el convertir a los repartidores en objeto de robos y asaltos. Vid. https://elpais.com/tecnologia/2015/11/29/actualidad/1448832870_199064.html
} 
Asimismo, han demostrado su utilidad para la búsqueda de personas, como Lifeseeker, dispositivo electrónico de búsqueda de personas sin cobertura en el celular incluso en condiciones atmosféricas adversas, escasa visibilidad o de noche, por ejemplo, personas perdidas en alta montaña, lo que reduce notablemente el tiempo y los costes de rescate. Por supuesto los usos privados comprenden también la vigilancia de zonas residenciales a través de cámaras incorporadas que permitan controlar en tiempo real las entradas y salidas del recinto de que se trate.

A todo ello debe añadirse la utilidad pública de estos instrumentos como medio para la vigilancia urbana para zonas con especial riesgo, lo cual supone aumentar las posibilidades de las cámaras estáticas y, por supuesto, tendría inevitables implicaciones jurídicas respecto a un sobredimensionamiento de la eventual afección de derechos ya prevista en la normativa que regula este tipo de grabaciones, en concreto la Ley Orgánica 4/1997, de 4 de agosto, por la que se regula la utilización de videocámaras por las Fuerzas y Cuerpos de Seguridad en lugares públicos ${ }^{15}$. A ella hay que añadir las posibilidades de utilización de estas cámaras colocadas en las pequeñas aeronaves no tripuladas como medio de protección de infraestructuras ${ }^{16}$, pudiendo alcanzar una visibilidad que no se podía obtener sin esa movilidad. Por supuesto, también son usadas ya en el control de la seguridad del tráfico de vehículos, pudiendo obtener imágenes estáticas o dinámicas utilizables en un procedimiento sancionador. No debe olvidarse tampoco la vigilancia transfronteriza a través

\footnotetext{
De hecho se creó ya algún tiempo el Amazon Prime Air, que en diciembre de 2016 demostró sus capacidades $\mathrm{y}$ ventajas: https://www.amazon.com/Amazon-Prime-Air/b?ie=UTF8\&node=8037720011

Este proyecto tiene centros de desarrollo en los Estados Unidos, en el Reino Unido, en Austria, en Francia y en Israel.

${ }^{15} \mathrm{Vid}$. https://www.aepd.es/media/guias/guia-videovigilancia.pdf

En esta guía se afirma lo siguiente respecto a los drones:

"El Grupo de Trabajo del artículo 29, del que forma parte la AEPD (Agencia Española de Protección de Datos), analizó este tipo de grabaciones utilizando drones en el Dictamen 01/2015, de 16 de junio de 2015, por lo que teniendo en consideración dicho Dictamen, y de forma resumida debe tenerse en cuenta lo siguiente:

- La operativa del dron habrá de cumplir con la normativa aplicable

- Valorar la posibilidad de realizar una Evaluación de Impacto de la Protección de Datos, atendiendo al tipo de dron y la tecnología de captación de datos para el tratamiento

- Evitar captar o tratar datos innecesarios a la finalidad pretendida

- Informar de la forma más apropiada y con carácter previo a los afectados, incluyendo una indicación clara de quién es el responsable y las finalidades del tratamiento, así como las indicaciones claras y específicas para el ejercicio de derechos

- Establecer medidas de seguridad apropiadas para los riesgos que representan el tratamiento pretendido

- Borrar y/o anonimizar cualquier dato innecesario".

${ }^{16}$ BARRIO ANDRÉS, Moisés, "Drones. Concepto...", op. cit., p. 41, señala a este respecto: "Protección de infraestructures críticas: comprendiendo la inspección y mantenimiento de instalaciones eléctricas, control e inspección de oleoductes y gaseoductos, observación de los flujos de tráfico y control de carreteres".
} 
de este tipo de aparatos, habitual por ejemplo en el espacio interfronterizo que separa Tijuana (México) de San Diego -y más en concreto, Chula Vista (Estados Unidos)-, por supuesto como instrumento de control frente a la inmigración ilegal.

En este ámbito de la utilización pública se incluye también el objeto central de nuestro análisis, es decir, el posible uso de estos aparatos para obtener datos sobre cierto tipo de delincuencia, en particular -y desde luego, no exclusivamente- en la de carácter ambiental, porque a veces el daño producido con trascendencia penal es de tales dimensiones o su situación específica es tan complicada que sería difícil para cualquier investigador acceder a él, o hacerlo con el carácter global e inmediato como el que puede tener lo obtenido a través de un dron. Debemos tener en cuenta que se multiplican las posibilidades, tanto como permita el avance mismo de la tecnología, por tanto no sólo se trata de obtener fotografías del lugar de la infracción, o videos en los que aparezcan, por ejemplo, los distintos puntos en los que puede haberse iniciado un incendio forestal provocado, sino también aplicar dispositivos que permitan una medición térmica del terreno, o una representación orográfica. En resumen, la obtención de datos relevantes jurídicamente en el caso concreto de que se trate ${ }^{17}$.

\section{4.- LOS DRONES COMO INSTRUMENTO DE INVESTIGACIÓN PENAL}

Si nos centramos en la perspectiva procesal penal, son diversas las consecuencias que debemos considerar y las cuestiones que deberán ser valoradas. En cuanto pensamos en la utilización de los drones en algunos procesos penales, desde luego, lo que se nos representa de inmediato es la investigación criminal, por las ventajas que aportan estos instrumentos.

De este modo los drones aparecen como una vía para la comprobación de los hechos, o de algunas particularidades de los mismos, como decía en el apartado anterior, puede ser particularmente decisiva su aplicación para determinar si un incendio forestal puede haber sido provocado, o si se ha originado fortuitamente, por ejemplo por partir de un rayo. No podemos olvidar tampoco que entre lo doloso y lo fortuito hay un amplio campo

\footnotetext{
17 Vid. ZAVRISNIK, Ales (Ed.), Drones and Unmanned Aerial Systems. Legal and Social Implications for
} Security and Surveilklance, Springer, New York, 2016. 
que es frecuente en la delincuencia ambiental y se refiere a la negligencia: piénsese en una barbacoa en la que se ha hecho un asado en una zona forestal y no se ha apagado debidamente ${ }^{18}$.

El dron facilita la investigación del foco del incendio y, con ello, obtiene datos que permiten construir una hipótesis fáctica, que puede servir para fundamentar la acusación o teoría del caso para abrir la fase de juicio oral y que después deberá ser corroborada en ésta última, con respeto de las exigencias constitucionales y legales, para poder desvirtuar la presunción de inocencia de un eventual acusado. Pero, aún más ampliamente, el uso de estas aeronaves no tripuladas puede servir para obtener datos muy útiles sobre la comisión de otro tipo de actividades criminales: fotografías o filmaciones dinámicas que nos muestren una reproducción de los hechos.

Pero, aparte de la comprobación de los hechos como una de las finalidades que pueden cumplir los drones en la fase de investigación, también pueden ser útiles para la otra gran finalidad de esta fase: la averiguación y persecución de delincuentes ${ }^{19}$. Por tanto, su utilidad puede revertir en el aspecto objetivo del objeto del proceso, pero también en su vertiente subjetiva: puede servir para atrapar a delincuentes en situación de flagrancia o a otros que, sin estar cometiendo el delito o habiéndolo terminado de cometer, están siendo buscados como consecuencia de datos ya existentes en la investigación misma.

A pesar de lo que alguna vez pueda haberse expuesto, no creo que pueda considerarse el dron en sí mismo como una diligencia de investigación penal, como no lo es el vehículo de cuatro ruedas (coche, carro, auto, camioneta) desde el que se puedan haber obtenido datos fundamentales para avanzar y profundizar en la indagación, pero sí puede ser, sin duda alguna un instrumento técnico con el que se facilita la obtención de fuentes de prueba $\mathrm{o}$, incluso, en algunos casos extremos, puede convertirse en un objeto de la investigación misma, pues no debemos descuidar la posibilidad de utilización aviesa del

\footnotetext{
${ }^{18}$ Lo dice muy claramente BUENO DE MATA, Federico, "Aspectos procesales del dron como diligencia de investigación tecnológica", en Derecho de los drones..., op. cit., p. 312: "La finalidad perseguida con la utilización del dron como diligencia de investigación tecnológica es la de captar imágenes, vídeos o la medición termográfica de una determinada zona con la finalidad de esclarecer quién y cómo perpetró la acción delictual o ilícita que se está investigando".

${ }^{19}$ El artículo 299 de nuestra anciana Ley de Enjuiciamiento Criminal (así es como se conoce oficialmente el Código procesal penal vigente en España) establece: "Constituyen el sumario las actuaciones encaminadas a preparar el juicio y practicadas para averiguar y hacer constar la perpetración de los delitos con todas las circunstancias que puedan influir en su calificación y la culpabilidad de los delincuentes, asegurando sus personas y las responsabilidades pecuniarias de los mismos.".
} 
dron mismo, convirtiéndolo en instrumento criminal en sí mismo, ya sea por la posibilidad de ser medio de transporte de armas que puedan ser activadas en pleno vuelo, o de convertirse en literal arma arrojadiza contra un objetivo criminal $^{20}$, con lo que el dron mismo puede convertirse en "cuerpo del delito".

\section{1.- REFERENCIA AL MARCO NORMATIVO VIGENTE}

Sin entrar en un estudio profundo sobre la regulación de estos instrumentos de investigación es conveniente subrayar algunos elementos normativos que en niveles distintos afectan a su aplicación, desde el ámbito internacional hasta el reglamentario interno, pasando por alguna importante norma de Derecho europeo. Debemos mencionar algunas de sus características más importantes para poder entender mejor el conjunto.

El Convenio de Chicago sobre aviación civil internacional ${ }^{21}$, a pesar de su antigüedad (1944) dedica su artículo 8 a las aeronaves sin piloto y dispone lo siguiente: "Ninguna aeronave capaz de volar sin piloto volará sin él sobre el territorio de un Estado contratante, a menos que se cuente con autorización especial de tal Estado y de conformidad con los términos de dicha autorización. Cada Estado contratante se compromete a asegurar que los vuelos de tales aeronaves sin piloto en las regiones abiertas a la navegación de las aeronaves civiles sean controlados de forma que se evite todo peligro a las aeronaves civiles". Es una llamada, pues, a que los Estados competentes desarrollen una normativa respecto al régimen jurídico de estos artefactos ${ }^{22}$.

En concreto, por lo que se refiere a España, la Ley 18/2014, de 15 de octubre, de aprobación de medidas urgentes para el crecimiento, la competitividad y la eficiencia ${ }^{23}$, entre otras muchas previsiones de índole diversa, posibilitó el inicio de ciertas operaciones civiles

20 Cfr. CHAMAYOU, Grégoire, Drone Theory, Penguin, New York, 2013; KREPS, Sarah, Drones. What everyone needs to know, Oxford University Press, New York, 2016.

$21 \quad$ Vid. http://www.sct.gob.mx/fileadmin/DireccionesGrales/DGAC/marco-juridico-y-regulatorionormativo/juridico/convenios/convenio-de-chicago.pdf

${ }^{22}$ Como recuerda, además, BARRIO ANDRÉS, Moisés, “Drones. Concepto...”, op. cit., p. 47, la OACI publicó la Circular 328-AN/190 (https://www.icao.int/Meetings/UAS/Documents/Circular\%20328_es.pdf).

Este documento de la Organización de la Aviación Civil Internacional dedica una parte, precisamente, a la protección del medio ambiente, pero se refiere a la eventual contaminación acústica procedente de estas aeronaves y así como la atmosférica que se pueda desprender de sus motores.

${ }^{23}$ BOE núm. 252, de 17 de octubre de 2014. 
aeronaves pilotadas por control remoto (art. 50) y se dejaba al Gobierno la determinación reglamentaria del régimen jurídico aplicable a las aeronaves civiles pilotadas por control remoto, así como a las operaciones y actividades realizadas por ellas (Disposición Final Segunda).

En la actualidad hay que atender al Real Decreto 1036/2017, de 15 de diciembre, por el que se regula la utilización civil de las aeronaves pilotadas por control remoto, y se modifican el Real Decreto 552/2014, de 27 de junio, por el que se desarrolla el Reglamento del aire y disposiciones operativas comunes para los servicios y procedimientos de navegación aérea y el Real Decreto 57/2002, de 18 de enero, por el que se aprueba el Reglamento de Circulación Aérea ${ }^{24}$. De esta regulación cabe destacar los siguientes elementos en cuanto a su ámbito de aplicación:

- Se aplica a aeronaves civiles pilotadas por control remoto (Remotedly Piloted Aircraft) cuya carga máxima sea inferior a los $150 \mathrm{~kg}$. excluidas de la normativa sobre operaciones aéreas especializadas o vuelos experimentales,

- También a las aeronaves civiles pilotadas por control remoto (RPA), cualquiera que sea su masa máxima al despegue, que realicen actividades de aduanas o policía,

- Se prevé también su aplicación para la búsqueda y salvamento de personas, lucha contra incendios, guardacostas o similares, salvo algunas exclusiones concretas que en resumen se refieren a una relajación de los requisitos para las actividades llevadas a cabo por las Fuerzas y Cuerpos de Seguridad, el Servicio de Vigilancia Aduanera, la Dirección General de Tráfico, o el Centro Nacional de Inteligencia.

En el texto articulado de este Real Decreto se contienen numerosas disposiciones sobre los siguientes aspectos:

- Requisitos de los sistemas de las aeronaves

- Condiciones para la utilización del espacio aéreo

\footnotetext{
${ }^{24}$ BOE núm. 316, de 29 de diciembre de 2017.
} 
Rio de Janeiro. Ano 13. Volume 20. Número 3. Setembro a Dezembro de 2019

Periódico Quadrimestral da Pós-Graduação Stricto Sensu em Direito Processual da UERJ

Patrono: José Carlos Barbosa Moreira (in mem.). ISSN 1982-7636. pp. 268-292 www.redp.uerj.br

- $\quad$ Requisitos de la operación

- $\quad$ Exigencias del personal

- Habilitación para operaciones aéreas o vuelos experimentales

Por su parte, mediante Resolución de 8 de marzo de $2019^{25}$, de la Dirección de la Agencia Estatal de Seguridad Aérea, se publican los medios aceptables de cumplimiento y material guía, aprobados para las operaciones con aeronaves pilotadas por control remoto, en virtud del Real Decreto 1036/2017, de 15 de diciembre. Esta norma establece los llamados "medios aceptables de cumplimiento", es decir, los criterios o estándares no obligatorios que aclaran o explican una forma de demostrar cumplimiento con un texto normativo, de manera que quien demuestre el cumplimiento de la norma correspondiente de esta forma, puede contar con la presunción de cumplimiento. Y el "material guía", "material no obligatorio que ayuda a explicar o ilustrar el significado de un requisito o especificación de un texto normativo y facilitar su interpretación".

A todo ello debe superponerse el Reglamento (UE) núm. 2018/1139²6, que armoniza por vía directa la regulación en los países miembros de la Unión Europea. Sobre los drones se destaca que las tecnologías de las aeronaves no tripuladas actualmente hacen posible una amplia gama de operaciones que deben ser objeto de normas que sean proporcionales al riesgo de la operación o del tipo de operación en concreto. Se exigen, por otro lado, requisitos operativos determinados para afrontar los riesgos que pueden representar las aeronaves no tripuladas para la seguridad operativa, la privacidad, la protección de datos personales, la seguridad en general o el medio ambiente. Tales requisitos se refieren al registro de aeronaves no tripuladas y de operadores de aeronaves no tripuladas. Y además, se establece que es necesario establecer sistemas nacionales de registro digitalizados, armonizados e interoperables en los que debe almacenarse información que incluya los mismos datos básicos sobre aeronaves no tripuladas y operadores de aeronaves

\footnotetext{
${ }^{25}$ BOE núm. 91, de 16 de abril de 2019.

${ }^{26} \mathrm{Vid}$. https://eur-lex.europa.eu/legal-content/ES/TXT/PDF/?uri=CELEX:32018R1139\&from=EN

Se trata del "Reglamento (UE) 2018/1139 del Parlamento Europeo y del Consejo de 4 de julio de 2018 sobre normas comunes en el ámbito de la aviación civil y por el que se crea una Agencia de la Unión Europea para la Seguridad Aérea y por el que se modifican los Reglamentos (CE) núm. 2111/2005, (CE) núm. 1008/2008, (UE) núm. 996/2010, (CE) núm. 376/2014 y las Directivas 2014/30/UE y 2014/53/UE del Parlamento Europeo y del Consejo y se derogan los Reglamentos (CE) núm. 552/2004 y (CE) núm. 216/2008 del Parlamento Europeo y del Consejo y el Reglamento (CEE) núm. 3922/91 del Consejo"
} 
no tripuladas registrados, cumpliendo la legislación de la Unión Europea y nacional aplicable en materia de privacidad y tratamiento de datos personales, y la información conservada en estos sistemas de registro debe ser fácilmente accesible ${ }^{27}$.

\section{2.- PLAN ESTRATÉGICO DEL GOBIERNO 2018-2021}

En la actualidad contamos también con un "Plan Estratégico para el desarrollo civil de los drones en España 2018-2021”, presentado por el Ministerio de Fomento el 19 de marzo de 2018. En este texto ${ }^{28}$ se analiza la situación del sector y se esbozan vías de desarrollo específicas, con algunas iniciativas concretas.

Respecto al análisis del estado del arte se ofrece una interesante visión de conjunto sobre el sector civil -no militar- de las aeronaves no tripuladas, haciendo hincapié en su versatilidad, en el desarrollo de la tecnología y en la reducción de costes. Según se afirma: se estima que en la Unión Europea existe un parque de entre 1 y 1,5 millones de drones de uso civil, aumento debido fundamentalmente a un fuerte crecimiento de los drones de uso recreativo, con incrementos superiores al 100\% anual en los últimos años. Conviene puntualizar la distinción que se hace entre los "drones autónomos", que no requieren la intervención humana durante la mayor parte de la operación y "los de control remoto", aquellos en los que el dron está controlado permanentemente por un piloto, que son los denominados en sentido estricto (RPAS). A corto plazo se destaca sobre todo la filmación de actividades nocivas para el medio ambiente: observación de plantas y animales, detección de vertidos, control actividades no permitidas y cartografía de masas forestales ${ }^{29}$.

El objetivo que se plantea es el perfeccionamiento de los drones para que puedan tener una mayor autonomía y puedan operar incluso fuera del alcance de la vista de quien los maneja. La inteligencia artificial aplicada a estos instrumentos podrá permitir la llamada "consciencia situacional" de estos artefactos y poder tomar decisión en consecuencia de las

\footnotetext{
27 Vid. más en detalle GONZÁLEZ BOTIJA, Fernando, Los drones y el derecho de la Unión Europea. Reglamento (UE) $n^{\circ}$ 2018/1139 y propuestas de EASA, Atelier, Barcelona, 2018.

${ }^{28} \mathrm{https} / / / \mathrm{www} . f o m e n t o . g o b . e s / e l-m i n i s t e r i o / p l a n e s-e s t r a t e g i c o s / d r o n e s-e s p a n i a-2018-2021$

29 En el informe (p. 21) se destaca que: "Las tendencias actuales en materia de IOT3 (Internet de las Cosas), Big Data, Inteligencia artificial y Aprendizaje Automático, entre otras, se irán integrando paulatinamente en el desarrollo de estas aeronaves y, al igual que las tecnologías previas, se traducirán en una mejora de sus prestaciones y una mayor flexibilidad para adaptarse a nuevos servicios y mejorar los ya existentes”.
} 
características de la situación en que se encuentren. De este modo se ampliará notablemente el campo de investigación y se perfeccionará la obtención y selección de los datos obtenidos, permitiendo además una búsqueda más específica a partir de la propia elaboración de los datos obtenidos. Un punto importante es la gestión del espacio donde operan los drones. Así se habla del futuro sistema de gestión del tráfico aéreo de baja altura, denominado U-Space (denominación del sistema europeo UTM6 ) ${ }^{30}$.

En cuanto a la observación de las cifras, se identifican tres actores principales: Estados Unidos, China y Europa. En el primero, Estados Unidos, la industria de los drones se desarrolló enormemente en la primera década de este siglo debido al impulso que tuvo esta tecnología en el sector militar, y que sigue suponiendo un $96 \%$ de las ventas de estas aeronaves en la actualidad. Sólo a partir de 2010 se expande su aplicación al ámbito civil, de manera muy amplia en el ámbito recreativo. España se encuentra aún en una fase de desarrollo incipiente y todavía muy atomizado. Sin embargo se es consciente del gran potencial europeo, tanto en la fabricación como en la utilización de estos instrumentos ${ }^{31}$.

Hay, además de la perspectiva analítica, un planteamiento estratégico integral, como se deduce del título mismo del documento. Se definen cuatro ejes principales:

- Implantación del marco normativo actual y desarrollo de la normativa futura

- Impulso al desarrollo empresarial y a la I+D+i del sector

- Divulgación de información sobre el sector

- Coordinación entre Administraciones Públicas

Se complementa todo ello con una serie de iniciativas concretas, entre las que a nuestros efectos, tal vez sea oportuno señalar el desarrollo de medios de cumplimiento y material guía para fabricantes, centros de formación y operadores; el desarrollo de medios electrónicos para la gestión de las operaciones; un plan de inspecciones para drones, centros

\footnotetext{
${ }^{30}$ Se menciona que entre las funciones más importantes del sistema $U$-Space se encuentran:

- La operación segura de drones, proporcionando un sistema de gestión de espacio aéreo y definiendo posibles limitaciones físicas de intrusión (geo-fencing).

- La gestión de la congestión del espacio aéreo de baja cota.

- La separación de obstáculos y la previsión de meteorología adversa para la operación segura de los drones.

- El seguimiento continuo de los vuelos, identificando las operaciones no autorizadas.

${ }^{31}$ Plan Estratégico..., op. cit., p. 43: "A pesar de esta heterogeneidad en los marcos normativos, el mercado de drones de uso civil de la Unión generó ingresos por un valor de 259 millones de euros en 201616, y se estima que la industria europea vaya ganando cuota de mercado mundial en los próximos 10 años potenciado, entre otras cuestiones, por la implantación de una normativa armonizada”.
} 
de formación y operadores; el desarrollo de medios de cumplimiento y material guía para protección de comunicaciones; el desarrollo de guías para la captura y tratamiento de datos obtenidos mediante drones...

Finalmente, se contempla el seguimiento del plan, con el nombramiento de un Comité de Dirección ${ }^{32}$ y comité más específicamente encargado de ello: el Comité de Coordinación y Seguimiento ${ }^{33}$, además de equipos más concretos dedicados a las distintas iniciativas. Debe puntualizarse que este Plan fue aprobado por un Ministerio de un Gobierno distinto del actual, por tanto habrá que observar atentamente cómo se adaptan las prioridades de este Plan a las previsiones del nuevo ejecutivo, aunque es razonable pensar que, aún con matizaciones o modificaciones, estará interesado en el desarrollo de la navegación aérea no tripulada y, más en particular, en su aplicación para la persecución de la delincuencia en la medida en que sus posibilidades lo permitan.

\section{3.- LOS DRONES EN LA LECRIM}

Todo lo expuesto hasta ahora casa mal con una legislación procesal penal cuya base estructural procede del 14 de septiembre de 1882, pese a los muchos avances que supuso en su día nuestra vieja Ley de Enjuiciamiento Criminal. Como es de suponer, desde su entrada en vigor hasta la actualidad son muy numerosas las reformas que han en ocasiones han supuesto pasos atrás y en otros han introducidos elementos de modernidad y de garantía muy positivos, sobre todo tras la influencia directa e indirecta de la Constitución de 1978 y la vinculación al Convenio europeo de los derechos humanos y las libertades fundamentales y a su Tribunal permanente encargado de la interpretación y la aplicación de tales derechos y libertades. También el Tribunal de Justicia, órgano -o en realidad, conjunto de órganos de la Unión Europea- que bien pronto se preocupó de la protección de los derechos

\footnotetext{
${ }^{32}$ Compuesto por el Ministro de Fomento, el Secretario de Estado de Infraestructuras, Transporte y Vivienda, la Secretaria General de Transporte, el Secretario de Estado de Investigación, Desarrollo e Innovación, el Secretario de Estado para la Sociedad de la Información y la Agenda Digital, el Secretario de Estado de Seguridad, el Presidente de INECO, el Director General de Aviación Civil, el Director General de Enaire, la Directora de la Agencia Estatal de Seguridad Aérea, el Secretario General de Ciencia e Innovación y Presidente del CDTI, y la Directora de la AEPD.

${ }^{33}$ El Comité de Coordinación y Seguimiento estará compuesto por la Dirección General de Aviación Civil, la Subdirección de Economía, Planificación y Medio Ambiente de INECO, así como los diferentes gerentes de iniciativas
} 
fundamentales, que más recientemente quedaron proclamados con fuerza de obligar en la Carta de Derechos Fundamentales. En definitiva, el contexto de aplicación de los antiguos artículos ha cambiado y ha habido ciertas actualizaciones que nos permiten la investigación y el enjuiciamiento de infracciones criminales a través de diversos -demasiadosprocedimientos que, con sus virtudes y sus defectos, se han ido acumulando uno al lado de los demás, sin justificación real alguna.

En el odre viejo de la Ley de Enjuiciamiento Criminal, en octubre de 2015 se introdujeron múltiples modificaciones. La más importante para lo que estamos examinando es la que introdujo la Ley Orgánica 13/2015, de 5 de octubre, de modificación de la Ley de Enjuiciamiento Criminal para el fortalecimiento de las garantías procesales y la regulación de las medidas de investigación tecnológica ${ }^{34}$. En esta Ley, entre otras medidas de gran interés e innovación se prevé la utilización de dispositivos técnicos de captaciones de la imagen, de seguimiento y de localización; la captación de imágenes en lugares o espacios públicos y la utilización de dispositivos o medios técnicos de seguimiento o localización (arts. 588 quinquies a 588 quinquies c LECrim), con una limitación temporal de la aplicación de la medida por tres meses máximo, aunque con posibilidad de prórroga ${ }^{35}$.

Esta regulación facilita la utilización de aeronaves no tripuladas para las finalidades que antes apuntaba, con grandes posibilidades de obtener datos para facilitar la comprobación del hecho punible y la averiguación de los posibles delincuentes ${ }^{36}$. Y debe ser completada con las importantes "Disposiciones comunes", contenidas en los artículos del 588 bis a al 588 bis k, y que básicamente contienen una concreción de las elementos de proporcionalidad que den paso a la aplicación lícita de estas vías de investigación. Ello supone una muy necesaria actualización de la regulación procesal penal de la investigación, con el problema que conlleva sin embargo, todo lo relacionado con las más novedosas tecnologías, que pronto pueden verse superadas por otras más evolucionadas. En todo caso,

\footnotetext{
${ }^{34}$ BOE núm. 239, de 6 de octubre de 2015

35 Vid. DÍAZ MARTÍNEZ, Manuel; LÓPEZ-BARAJAS PEREA, Inmaculada, (Dirs.) La nueva reforma procesal penal. Derechos fundamentales e innovaciones tecnológicas, Tirant lo Blanch, Valencia, 2018.

${ }^{36}$ Es preciso añadir, con BUENO DE MATA, Federico, "La utilización de drones como diligencia de investigación tecnológica: consecuencias probatorias", La Ley, 2553/2018, que "Respecto al uso del dron como diligencia de investigación policial en esta ley orgánica es necesario apuntar que no hay una alusión concreta a los drones de manera concreta, debido al carácter abierto de la norma".
} 
la manifiesta insuficiencia normativa que teníamos hasta la entrada en vigor de estas normas queda en gran parte compensada.

\section{4.- EVENTUAL AFECCIÓN A DERECHOS FUNDAMENTALES}

El mencionado Reglamento europeo núm. 2018/1139 sobre normas comunes en el ámbito de la aviación civil ya se preocupaba de la relación que puede tener la actividad de la aeronaves no tripuladas con los derechos fundamentales, y por ello, ya en sus considerandos iniciales afirma lo siguiente: "Las normas relativas a las aeronaves no tripuladas deben contribuir al cumplimiento de los derechos pertinentes garantizados en virtud del Derecho de la Unión, y en particular el derecho al respeto de la vida privada y familiar, establecido en el artículo 7 de la Carta de los Derechos Fundamentales de la Unión Europea, y el derecho a la protección de datos de carácter personal, establecido en el artículo 8 de dicha Carta y en el artículo 16 TFUE y según lo regulado en el Reglamento (UE) 2016/679 del Parlamento Europeo y del Consejo".

Son muchos los derechos fundamentales que se pueden ver afectados por el uso de los drones para la investigación penal, pero en especial tres: el derecho a la intimidad personal y familiar, el derecho a la propia imagen, así como la inviolabilidad del domicilio. Junto a ellos, también la tutela judicial efectiva, el derecho a utilizar los medios de prueba pertinentes y, si nos ponemos en los casos extremos antes aludidos, hasta la propia integridad física o la vida, si el propio dron es utilizado como un instrumento de agresión. Las mencionadas previsiones de la LECrim contenidas en las disposiciones comunes, además de algunas otras normas establecidas en los capítulos siguientes, intentan precisamente dar al juez instrumentos de certeza para adoptar sus decisiones de autorización de determinadas medidas de investigación y, en consecuencia, fuera de esos límites la consecuencia deberá ser la inutilización de la información obtenida por vulneración del núcleo duro de la Constitución, en lo que hemos dado en llamar de manera genérica "prueba ilícita"37.

El derecho fundamental que más riesgos tiene de verse afectado es el de la intimidad, ya que los aparatos voladores con sus cámaras fotográficas, videográficas o de medición de diversas variables, nos sitúan en un plano más compleja en la protección de este

\footnotetext{
${ }^{37}$ El articulo 19 de la Ley Orgánica del Poder Judicial establece, por influencia directa del Tribunal Constitucional, que: "En todo tipo de procedimiento se respetarán las reglas de la buena fe. No surtirán efecto las pruebas obtenidas, directa o indirectamente, violentando los derechos o libertades fundamentales.".
} 
derecho fundamental. Se tenía claro que respecto a lo que ocurra en un lugar público, por ejemplo si alguien observa la comisión de un delito, su declaración testifical no infringirá ningún derecho y tendrá plena validez para condenar. Pero otra cosa es la observación desde fuera -o incluso desde arriba de terrazas o patios- de actividades particulares de alguien que desarrolla su privacidad sin querer verse vigilado por cámaras de cuya presencia incluso es probable que no sea consciente ${ }^{38}$.

A la inviolabilidad del domicilio como una garantía frente a la actividad probatoria obtenida a través de drones se refiere específicamente la sentencia de la Sala 2. ${ }^{a}$ de nuestro Tribunal Supremo núm. 329/2016, 20 de abril de 2016. La doctrina es favorable a la interpretación amplia del derecho fundamental: "Nuestro sistema constitucional no alza ningún obstáculo para llevar a cabo, en el marco de una investigación penal, observaciones y seguimientos en recintos públicos. A juicio de la Sala, sin embargo, la fijación del alcance de la protección constitucional que dispensa el art. 18.2 de la CE sólo puede obtenerse adecuadamente a partir de la idea de que el acto de injerencia domiciliaria puede ser de naturaleza física o virtual. En efecto, la tutela constitucional del derecho proclamado en el apartado 2 del art. 18 de la CE protege, tanto frente la irrupción inconsentida del intruso en el escenario doméstico, como respecto de la observación clandestina de lo que acontece en su interior, si para ello es preciso valerse de un artilugio técnico de grabación o aproximación de las imágenes. El Estado no puede adentrarse sin autorización judicial en el espacio de exclusión que cada ciudadano dibuja frente a terceros. Lo proscribe el art. 18.2 de la CE. Y se vulnera esa prohibición cuando sin autorización judicial y para sortear los obstáculos propios de la tarea de fiscalización, se recurre a un utensilio óptico que permite ampliar las imágenes y salvar la distancia entre el observante y lo observado"39.

\footnotetext{
${ }^{38}$ Vid. AMER MARTÍN, Alicia, "El derecho a la intimidad y la prueba obtenida mediante drones", en: http://noticias.juridicas.com/conocimiento/articulos-doctrinales/11152-el-derecho-a-la-intimidad-y-la-pruebaobtenida-mediante-drones/

${ }^{39}$ Continúa la mencionada sentencia: "la protección constitucional de la inviolabilidad del domicilio, cuando los agentes utilizan instrumentos ópticos que convierten la lejanía en proximidad, no puede ser neutralizada con el argumento de que el propio morador no ha colocado obstáculos que impidan la visión exterior. El domicilio como recinto constitucionalmente protegido no deja de ser domicilio cuando las cortinas no se hallan debidamente cerradas. La expectativa de intimidad, en fin, no desaparece por el hecho de que el titular o usuario de la vivienda no refuerce los elementos de exclusión asociados a cualquier inmueble. Interpretar que unas persianas no bajadas o unas cortinas no corridas por el morador transmiten una autorización implícita para la observación del interior del inmueble, encierra el riesgo de debilitar de forma irreparable el contenido material del derecho a la inviolabilidad domiciliaria.".
} 
Por otro lado, el indebido tratamiento de la obtención de datos personales por esta vía puede también vulnerar derechos fundamentales ${ }^{40}$, por ella la propia LOPJ en la reforma mencionada se ha preocupado de atender este riesgo ${ }^{41}$. Así el artículo 236.1 quinquies establece que "Los Jueces y Tribunales, y los Letrados de la Administración de Justicia conforme a sus competencias procesales, podrán adoptar las medidas que sean necesarias para la supresión de los datos personales de los documentos a los que puedan acceder las partes durante la tramitación del proceso siempre que no sean necesarios para garantizar su derecho a la tutela judicial efectiva”. Más específicamente el GT29 o Grupo de Trabajo del artículo 29 formado por las Autoridades Europeas de protección de Datos aprobó en el año 2015 un Dictamen conjunto sobre drones, en el que se analizan los riesgos y las incidencias que la utilización de RPAS pueden causar en la privacidad y la protección de los datos de las personas físicas ${ }^{42}$.

Me refería también a la puesta en peligro de la incolumidad del derecho a la propia imagen, pues los drones pueden captarla sin autorización alguna del interesado ${ }^{43}$. Conforme ha afirmado el Tribunal Constitucional español, en sentencia núm, 14/2003, de 28 de enero: "En su dimensión constitucional, el derecho a la propia imagen proclamado en el art.18.1 CE se configura como un derecho de la personalidad, derivado de la dignidad humana y dirigido a proteger la dimensión moral de las personas, que atribuye a su titular un derecho a determinar la información gráfica generada por sus rasgos físicos personales que puede tener difusión pública. La facultad otorgada por este derecho, en tanto que derecho fundamental, consiste en esencia en impedir la obtención, reproducción o publicación de la propia imagen por parte de un tercero no autorizado, sea cual sea la finalidad --informativa,

\footnotetext{
${ }^{40}$ Vid. DAVARA RODRÍGUEZ, Miguel Ángel, "Los drones y la privacidad”, El Consultor de los Ayuntamientos, núm. 15, agosto 2015, Ref. 1845/2015, p. 1845.

${ }^{41}$ En la línea de la Diretiva (UE) 2016/680 del Parlamento Europeo y del Consejo, de 27 de abril de 2016, relativa a la protección de las personas físicas en lo que respecta al tratamiento de datos personales por parte de las autoridades competentes para fines de prevención, investigación, detección o enjuiciamiento de infracciones penales o de ejecución de sanciones penales, y a la libre circulación de dichos datos y por la que se deroga la Decisión Marco 2008/977/JAI del Consejo.

${ }^{42}$ Dictamen 01/2015 sobre la privacidad y la protección de datos en relación con la utilización de aviones no tripulados (drones).

Vid. http://www.aspectosprofesionales.info/2015/06/dictamen-012015-sobre-la-privacidad-y.html

${ }^{43}$ Vid. SAN MIGUEL RODRÍGUEZ, Isabel, "Relevancia jurídico penal de la captación de imágenes por drones", Noticias jurídicas, 7 de julio de 2017.

http://noticias.juridicas.com/conocimiento/articulos-doctrinales/12139-relevancia-juridico-penal-de-lacaptacion-de-imagenes-por-drones/
} 
comercial, científica, cultural, etc.-- perseguida por quien la capta o difunde (TC SS 81/2001, de 26 Mar., FJ 2; 139/2001, de 18 Jun., FJ 4; 83/2002, de 22 Abr., FJ 4)”.

Aunque normalmente el conflicto se plantea este derecho y el derecho de los medios de comunicación a reproducir la imagen de un sujeto. También debe ser relevante respecto a la captación de imágenes por aeronaves no tripuladas. Sin embargo, no hay duda que también la administración de la justicia es un interés público constitucionalmente relevante que debe ser ponderado con ese derecho fundamental. Y eso es justamente lo que hace la LECrim, pues la captación de imágenes por las autoridades públicas no puede ser indiscriminada, sino que debe atenerse a ciertos límites, mucho más lábiles que los que se aplican a otros derechos fundamentales, pero no inexistes. El artículo 588.1 quinquies a dispone que "La Policía Judicial podrá obtener y grabar por cualquier medio técnico imágenes de la persona investigada cuando se encuentre en un lugar o espacio público, si ello fuera necesario para facilitar su identificación, para localizar los instrumentos o efectos del delito u obtener datos relevantes para el esclarecimiento de los hechos", por tanto debe haber una finalidad legítima en la obtención de las imágenes. Aclara aún más la cuestión el apartado segundo, de manera razonable a mi entender: "La medida podrá ser llevada a cabo aun cuando afecte a personas diferentes del investigado, siempre que de otro modo se reduzca de forma relevante la utilidad de la vigilancia o existan indicios fundados de la relación de dichas personas con el investigado y los hechos objeto de la investigación". Como se ve, se puede captar la imagen de terceros, pero siempre que haya base material suficiente.

\section{5.- DRONES Y MEDIOS DE PRUEBA: LAS DIFICULTADES DE UNA}

\section{LECRIM DEL SIGLO XIX}

Cuando cambiamos de perspectiva y atendemos a cómo se puede introducir en el plenario la prueba obtenida a través de estos medios de captación aérea de datos nos aparece de nuevo el problema de tener una norma antigua, que ha sido objeto de actualizaciones parciales, como "parcheados y zurcidos" que producen ciertas incoherencias, incluso respecto a su hermana, mucho más joven, la Ley de Enjuiciamiento Civil. 
La cuestión se centra en que así como se ha introducido una regulación detallada de nuevas diligencias de investigación basadas en las tecnologías digitales (Capítulos IV-X, Título VIII, Libro II LECrim), por tanto cauces por los que se puedan obtener fuentes de prueba, no ha habido la consiguiente actualización respecto a la vía de entrada de esas fuentes de prueba al núcleo del proceso. Dicho de otra manera, los medios de prueba siguen siendo los mismos en el proceso penal, mientras que la Ley que disciplina el proceso civil añadió en el año 2000 expresamente la prueba informática y la prueba videográfica (arts. 299.2 $2^{44}$ y de forma algo más amplia en los arts. 382 a 384). Entonces la cuestión que se plantea es por qué vía pueden entrar los datos obtenidos a través de las cámaras u otros aparatos incorporados al dron.

Podría entenderse que la Ley de Enjuiciamiento Civil opera como regulación subsidiaria, y al no existir medio específico en la legislación procesal penal sería de aplicación el artículo 4 LEC ("En defecto de disposiciones en las leyes que regulan los procesos penales, contencioso-administrativos, laborales y militares, serán de aplicación, a todos ellos, los preceptos de la presente Ley" ${ }^{\text {"45). }}$, atendiendo que los elementos captados son de naturaleza digital, podría aplicarse la Ley 18/2011, de 5 de julio, reguladora del uso de las tecnologías de la información y la comunicación en la Administración de Justicia y la disposición adicional primera de la Ley 42/2015, de 5 de octubre, que al regular la utilización de los medios telemáticos para la presentación de "escritos y documentos"46. La Ley 59/2003, de 19 de diciembre, de firma electrónica, a su vez, define qué se considera "documento electrónico": "Se considera documento electrónico la información de cualquier naturaleza en forma electrónica, archivada en un soporte electrónico según un formato determinado y susceptible de identificación y tratamiento diferenciado" (art. 3.5).

En lo penal, en definitiva, se sigue teniendo la ventaja de la previsión de conceptos amplios e indeterminados. Así ocurre con el de "documento" del artículo 26 del

\footnotetext{
44 “También se admitirán, conforme a lo dispuesto en esta Ley, los medios de reproducción de la palabra, el sonido y la imagen, así como los instrumentos que permiten archivar y conocer o reproducir palabras, datos, cifras y operaciones matemáticas llevadas a cabo con fines contables o de otra clase, relevantes para el proceso".

${ }^{45}$ El encabezamiento del articulo es precisamente "Carácter supletorio de la Ley de Enjuiciamiento Civil".

${ }^{46}$ No debe confundirse en mi opinión laforma de presentación de los escritos ante los órganos jurisdiccionales con la naturaleza del medio de prueba de que se trate. Por tanto, no creo que sea de utilidad para dar respuesta a nuestra pregunta el Real Decreto 1065/2015, de 27 de noviembre, sobre comunicaciones electrónicas en la Administración de Justicia en el ámbito territorial del Ministerio de Justicia y por el que se regula el sistema LexNET.
} 
Código Penal (Todo soporte material que exprese o incorpore datos, hechos o narraciones con eficacia probatoria o cualquier otro tipo de relevancia jurídica) o "cuerpo del delito" del art. 334 LECrim ("armas, instrumentos o efectos de cualquiera clase que puedan tener relación con el delito y se hallen en el lugar en que éste se cometió, o en sus inmediaciones, o en poder del reo, o en otra parte conocida"). Esto último para el caso de que la aeronave no tripulada sea utilizada como instrumento de agresión.

Nos interesa sobre todo la primera opción, de modo que el material probatorio obtenido a través del dron, sean imágenes, diagramas, esquemas cartográficos, etc., podrá entrar como prueba documental, con las consecuencias que ello conlleva, y que pueden suponer algunos problemas. Si en principio es así, simplemente se presentará en el proceso el documento, sin obligación ninguna de que nadie vaya a someterse a interrogatorio cruzado acerca de los modos de adquisición de ese documento, lo cual puede producir indefensiones. En los casos en que la información sea especializada, sería más razonable requerir informe pericial, para permitir que el perito designado sea obligado a comparecer y a someterse a las cuestiones que las partes tengan a bien preguntar -y el tribunal no declarar impertinentes ni innecesarias-. El contenido de la contradicción en estos casos sería más pleno, y por tanto lo ideal sería una regulación autónoma de un medio de prueba digital ${ }^{47}$, en el que no baste la presentación de los datos al plenario, sino su explicación y "vulgarización” por parte del especialista para comprensión de las partes y del juzgador ${ }^{48}$. Sería más armónica esta solución con el derecho a un proceso sin dilaciones indebidas que partir de una prueba documental sobre la que deba pedirse "prueba sobre prueba" a posteriori, es decir, una pericia que explique los pormenores de lo que se ha presentado y que en principio no es fácilmente entendible para quien no tenga conocimientos especializados.

\section{6.- ALGUNOS PROBLEMAS DE VALORACIÓN PROBATORIA}

\footnotetext{
47 CARRIER, Brian, SPAFFORD, Eugene H., "Getting Physical with the Digital Investigation Process", International Journal of Digital Evidence, Fall 2003, Volume 2, Issue 2, definen la prueba digital del modo siguiente: "Digital data that can establish that a crime has been committed, can provide a link between a crime and its victim, or can provide a link between a crime and its perpetrator. The data in memory, on the hard disk, or in a cell phone are examples of digital evidence".

48 Cfr. GARRIE, Daniel B., MORRISSY, J., David, "Digital Forensic Evidence in the Courtroom: Understanding Content and Quality", Northwestern Journal of Technology and Intellectual Property, núm. $121,2014$.
} 
Nos encontramos, en definitiva con la obtención de imágenes o filmaciones pertinentes y útiles para los fines probatorios que son sometidos a contradicción en el juicio oral y que el juzgador debe apreciar individual y conjuntamente con el resto de las eventuales pruebas que consten en las actuaciones. Con ello entramos en el campo espinoso de los riesgos valorativos en la construcción de la narración judicial a partir del material probatorio controvertido.

El principal riesgo es, aunque parezca absurdo, el de la confusión entre el medio de prueba y la realidad. Dicho de otro modo, el riesgo es que la aportación de imágenes y sobre todo videograbaciones nos parezca que nos trae a la sala de vista la verdad misma. Lo que verdaderamente ocurrió. Por tanto, lo que le interesa al juez para fundamentar su declaración sobre los hechos y no apartarse de lo que ocurrió en un día y en un lugar determinados. Pero, la verosimilitud de lo que vemos en estos casos, del lugar de los vertidos, de la posición de una determinada persona que parece sospechosa de haber provocado un incendio, no nos debe llevar a la conclusión de que traemos el proceso la realidad misma.

Como mucho traemos una porción de imágenes sobre el lugar de los hechos y ello no nos debe hacer olvidar que toda prueba es indirecta. Incluso la prueba videográfica o la prueba digital. La aportación de imágenes estáticas, de vídeo o incluso de otro tipo de datos como los orográficos o termográficos no serán sino una base cognitiva parcial sobre la que construir la narración sobre los hechos contenida en la sentencia. Por un lado debemos asegurarnos de que no ha habido problemas en el aseguramiento de la prueba, es decir, en la cadena de custodia de los datos aportados, pero además debemos ser conscientes del efecto de enmarcamiento (framing) que inevitablemente se produce con este tipo de pruebas ${ }^{49}$. Ello sin descartar tampoco los posibles sesgos psicológicos que se pueden derivar de un efecto de embelesamiento acrítico respecto a lo que nos viene de las tecnologías de información y comunicación. No se trata de poner en duda el procedimiento de valoración probatoria, sino de avisar para tratar de poner las debidas defensas que nos eviten desviarnos de la simple verdad que tratamos de dilucidar ${ }^{50}$.

\footnotetext{
${ }^{49}$ Cfr. FEIGENSON, Neal, Law on Display: The Digital Transformation of Legal Persuasion and Judgment, New York University Press, 2009.

${ }^{50}$ Es obligada la cita de TARUFFO, Michele, Simplemente la verdad: El juez y la construcción de los hechos, Marcial Pons, Madrid, 2010.
} 


\section{REFERENCIAS:}

ALONSO PUIG, Alejandro, Drones profesionales. Usos y Técnica, Quark Robotics, 2016.

AMER MARTÍN, Alicia, "El derecho a la intimidad y la prueba obtenida mediante drones", en: http://noticias.juridicas.com/conocimiento/articulos-doctrinales/11152el-derecho-a-la-intimidad-y-la-prueba-obtenida-mediante-drones/

BARRIO ANDRÉS, Moisés, "Drones. Concepto, clases e historia. Usos actuales. El Derecho de los drones", en Derecho de los drones (Dir. Moisés Barrio Andrés), La Ley, Madrid, 2018.

BONET NAVARRO, José, "La tutela judicial de los derechos no humanos. De la tramitación electrónica al proceso con robots autónomos", CEFLegal: revista práctica de derecho. Comentarios y casos prácticos, núm. 208, 2018, pp. 55-92,.

BROCKMAN, John (Ed.), Possible Minds. Twenty-Five Ways of Looking at AI, Penguin Press, New York, 2019.

CARRIER, Brian, SPAFFORD, Eugene H., "Getting Physical with the Digital Investigation Process", International Journal of Digital Evidence, Fall 2003, Volume 2, Issue 2.

CHACE, Calum, Surviving AI, Three Cs., 2015.

CHAMAYOU, Grégoire, Drone Theory, Penguin, New York, 2013; KREPS, Sarah, Drones. What everyone needs to know, Oxford University Press, New York, 2016.

CHOPRA, Samir, WHITE, Laurence F., A legal Theory for Autonomous Artificial Agents, The University of Michigan Press, Ann Arbor, 2011.

CORTINA ORTS, Adela. "El estatuto de la ética aplicada. Hermenéutica crítica de las actividades humanes", Isegoría, núm. 13, 1996, pp. 119-134.

DAVARA RODRÍGUEZ, Miguel Ángel, "Los drones y la privacidad”, El Consultor de los Ayuntamientos, núm. 15, agosto 2015, Ref. 1845/2015, p. 1845.

DÍAZ MARTÍNEZ, Manuel; LÓPEZ-BARAJAS PEREA, Inmaculada, (Dirs.) La nueva reforma procesal penal. Derechos fundamentales e innovaciones tecnológicas, Tirant lo Blanch, Valencia, 2018.

FEIGENSON, Neal, Law on Display: The Digital Transformation of Legal Persuasion and Judgment, New York University Press, 2009. 
GARRIE, Daniel B., MORRISSY, J., David, "Digital Forensic Evidence in the Courtroom:

Understanding Content and Quality", Northwestern Journal of Technology and Intellectual Property, núm. 121, 2014.

GONZÁLEZ BOTIJA, Fernando, Los drones y el derecho de la Unión Europea. Reglamento (UE) $n^{\circ}$ 2018/1139 y propuestas de EASA, Atelier, Barcelona, 2018.

JORDAN, John, Robots, MIT Press, Cambridge, 2016.

KAPLAN, Jerry, Artificial Intelligence. What everyone needs to know, Oxford University Press, New York, 2016.

LORENZETTI, Ricardo Luis, y LORENZETTI, Pablo, Principios e instituciones de Derecho ambiental, La Ley, Madrid, 2019.

NIEVA FENOLL, Jordi, Inteligencia artificial y proceso judicial, Marcial Pons, Madrid, 2018

PAGALlO, Ugo, The Laws of Robots. Crimes, Contracts, and Torts, Springer, Dordrect, 2013.

RUSSELL, Stuart J., NORVIG, Peter, Artificial Intelligence. A Modern Approach, Pearson, $3^{\text {rd }}$ ed., Harlow, 2016.

SAN MIGUEL RODRÍGUEZ, Isabel, "Relevancia jurídico penal de la captación de imágenes por drones", Noticias jurídicas, 7 de julio de 2017.

SCHWAB, Klaus, La cuarta revolución industrial, Debate, Barcelona, 2016.

TARUFFO, Michele, Simplemente la verdad: El juez y la construcción de los hechos, Marcial Pons, Madrid, 2010.

TEGMARK, Max, Life 3.0. Being human in the age of Artificial Intelligence, Penguin, New York, 2018.

WALTON, Douglas, Argumentation Methods for Artificial Intelligence in Law, Springer, New York, 2005.

ZAVRISNIK, Ales (Ed.), Drones and Unmanned Aerial Systems. Legal and Social Implications for Security and Surveilklance, Springer, New York, 2016. 